\title{
Creating an online mathematics and statistics community of learners
}

\author{
Rachel Hilliam* and Derek Goldrei \\ The Open University \\ ${ }^{*}$ Corresponding Author: Rachel.Hilliam@open.ac.uk
}

Keywords: Community of learners; Student Experience.

\begin{abstract}
There is an increasing focus within Higher Education on the wider student experience. Student engagement and a well-developed community are associated with greater levels of retention, student satisfaction and success. Whilst creating opportunities for students to engage with each other and staff may be easier in a face-to-face environment, the School of Mathematics and Statistics at The Open University has a long tradition of engaging distance learning students outside the 'classroom' environment. As the opportunities for face-to-face engagement have declined over time, the School has needed to adapt how this support is provided. One such initiative was to provide a subject forum with the specific remit of offering advice on module choice - the module advice forum. This paper shows how the forum fulfils a set of criteria which define a bounded learning community. Since its creation in the early 90's the forum has flourished and now provides students with the opportunity to engage more fully in issues such as curriculum development and delivery of student support. The key to its success is the wide-ranging community which contributes, besides the students themselves: this includes academics, part-time tutors and advisory student support staff, who all have their 'academic home' in the School of Mathematics and Statistics. The forum is housed on a Study website which provides dedicated resources to which students are referred via the forum to answer specific questions regarding module
\end{abstract}

choice at the appropriate point in their student journey.

\section{Introduction}

University education should be a holistic experience with the aim of not only producing independent learners, but providing the space for emotional, social and intellectual development. Creating a community of learners where a sense of identity and belonging can be established, by developing networks and relationships with fellow students, is key to improving student retention (Crosling et al, 2008). Many very able students leave higher education for non-academic reasons (Kuh et al, 2008). Foster et al (2012) had several recommendations to counteract this attrition including: helping students make moreinformed decisions about choosing the right course; good relationships and communications with staff; improving social integration; and improving a sense of belonging to a programme.

One way to establish this sense of belonging is through communities. Many work-based papers have been written which use the Lave and Wenger (1991) communities of practice model leading to new ways of working. Wenger, (1998) stated that there are three components to a community of practice model, these being that participants:

- are engaged in a joint enterprise,

- have common access to a shared repertoire of resources, 
- maintain relationships through mutual engagement.

Such communities are generally controlled by the participants with no hierarchical structure. However, in a learning context Wilson et al (2004) argue that, within a curriculum framework, a more bounded approach is needed, and the formation of such a community takes leadership, support and facilitation. The curriculum in this context is not necessarily a piece of learning such as an individual module, but could be a much wider programme of study such as a degree, for example.

In this paper we extend this idea of a bounded learning community and focus on a wider learning community; that is any student who is registered with the Open University and is studying or interested in studying any of the OU's mathematics or statistics modules, together with the staff who support them. In this paper we show how the School of Mathematics and Statistics has endeavoured to satisfy the seven proposed features of the framework for bounded learning communities (Wilson et al, 2004), these being:

1. Shared goals

2. Safe and supportive conditions

3. Collective identity

4. Collaboration

5. Respective inclusion

6. Progressive discourse towards knowledge building

7. Mutual appropriation.

The shared goal in this instance is providing advice and guidance for students who are choosing to study mathematics and statistics modules. However, the forum, which is the main focus of this paper and which supports this community, offers a much broader platform for wider student engagement.

Higher Education Institutions are looking for a variety of ways to foster a culture of partnership in student engagement. This means not only providing students with the opportunity to give feedback on their learning experience, but also to ensure that the feedback is listened to, valued and acted upon (Howson, 2014). It is important to create a culture where students feel that staff encourage feedback; and this works most effectively when all staff, that is, academics, student support and administrative staff, work collaboratively together to ensure students are aware of the opportunities to participate in engagement (Zhao \& Kuh, 2004).

This paper outlines a way in which The School of Mathematics and Statistics engages all such categories of staff linked to the School to create a bounded community of learners adhering to these seven principles in the framework.

\section{The mathematics and statistics learning community}

The mathematics and statistics curriculum covers four main areas of pure and applied mathematics, statistics and mathematical education at undergraduate level, together with pure and applied mathematics at postgraduate level. There are a number of choices regarding module study which students make at each point in their journey through their qualifications, as is the case at many institutions. However, the open nature of the OU provides the opportunity for students to study modules which form part of a qualification also as individual stand-alone units of study or, indeed, as part of other degree programmes. This flexibility means that advice and guidance relating to the suitability of modules for individual students is important. In addition, the distance learning nature of $\mathrm{OU}$ study means that face-to-face opportunities in which to engage students to help with module choice are rare.

\section{Background}

In the early years of the Open University, faceto-face annual meetings were held in numerous centres across the country to help students to plan their study routes. These were wellattended and lively meetings which gave students the chance to talk to academics, support staff and, indeed, each other about the content of modules and to discuss their study options. In particular, students had the opportunity to discuss their career aspirations and relevant module choices, the pre-requisite knowledge and skills required for each module, the nature of each module and how to optimise their success on it.

Over time, attendance at these meetings started to dwindle, so that as use of the internet became more widespread in the 1990s, the School of Mathematics and Statistics capitalised on this new medium by setting up an 
online module advice forum to augment and, increasingly, provide an alternative to the faceto-face events.

The forum aimed to offer peer support and advice, in conjunction with expert input from members of the School and subject-specialist educational advisors, therefore ensuring mutual engagement on the joint enterprise of module choice.

In order to provide shared repertoire, resources that assisted students with their module choices were also assembled and developed. For example, tables of examination results and student satisfaction ratings on individual modules were built up over several years, so that students could easily observe trends and use these to help inform their study planning. In order to deliver such information to students in an efficient way the School created a website (the mathematics and statistics programme site) to augment the University's official webpages. These resources were highlighted in forum discussions so that students and staff could engage in module choice discussions based on historical data

\section{The study site}

In 2017 the OU launched study websites, which would be online spaces with the aim of providing a home website for students throughout their qualification, as a complement to their existing individual module websites. By this time the School had built up a substantial number of online resources in its programme site and was able to transfer these resources to the Study Site for mathematics and statistics.

Each study site is split into six sections: STUDY HOME, CONNECT, DISCOVER, SKILLS, PLAN and SUCCEED, which are generic to all subject sites (Figure 1). The content which populates each section is at the discretion of the owning curriculum team, except for STUDY HOME which conforms to a standard template, and includes links to appropriate media sites: in the case of Mathematics and Statistics, these latter are the School's twitter feed and the Faculty's Facebook pages.

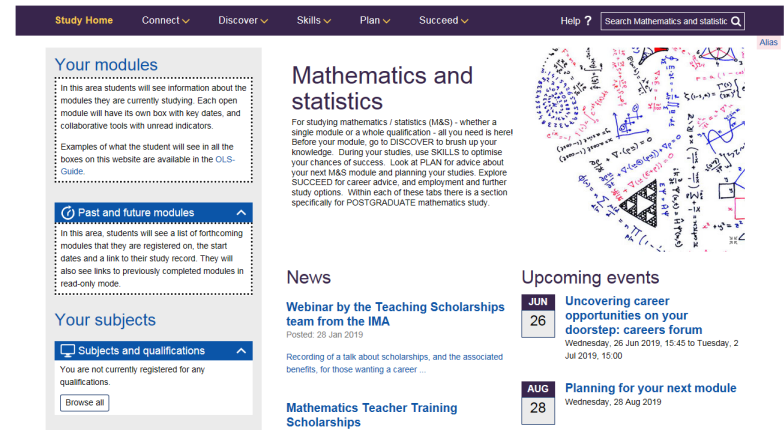

Figure 1 The mathematics and statistics subject site

The School of Mathematics and Statistics used this opportunity to develop the study site as a one-stop shop exploiting all the resources that it had already been using for many years to aid the discussion around module choice in the forum. In addition, it was able to arrange these assets in such a way as to mirror, support and enhance the student journey, from the first point of contact with the OU through to the point when the student achieves their qualification (Hilliam et al 2019b).

This site became the obvious place to house the module advice forum bringing all the resources needed to support the focus of the bounded learning community, that of module choice, into one website.

\section{Members of the Mathematics and Statistics learning community}

The School of Mathematics and Statistics at the OU comprises around 50 FTE academic staff and 500 part-time tutors, and it provides learning opportunities for around 20,000 students studying mathematics and statistics material. Each part-time tutor works directly with students, providing correspondence tuition for around 20 students on an individual module. Tinto (2004) stated that "Students who are actively involved with peers, faculty and staff especially in learning activities - are more likely to learn, persist and graduate." By focussing the forum on module choice, each member of the community has an equally valid and different perspective to contribute and students are able to easily engage with a wide range of staff.

There is a third group of staff who also contribute to the forum and form a vital part of this learning community, that is the educational advisors. In 2014 the university created subjectfocussed Student Support Teams (SSTs) to 
provide pastoral support for all students studying a particular discipline. At the time of creation the Mathematics and Statistics SST comprised around 35 advisory staff and had the responsibility of providing the full range of pastoral support for all mathematics and statistics students. Examples of such support include: additional requirements for students with disabilities; future study planning; registration, assessment and policy queries; and funding issues including student loans. The School and its SST saw the alignment of pastoral support with curriculum as an opportunity to establish a strong partnership mode of working (Hilliam et al 2019a). The SST staff soon became regular contributors to the module advice forum, being able to give advice on registration technicalities, for example, and over time became increasingly helpful with module choice advice.

This range of contributors ensures that there is a diversity of participants offering different perspectives regarding module choice, thereby satisfying criterion 5 of respective inclusion which requires a learning community to accommodate diversity of membership, opinions and perspectives (Wells, 1999).

\section{The focus for the bounded learning community}

Each individual module has its own individual forum which is time-dependent on the presentation period for that particular student cohort studying the module. Tutorials, both online and face-to-face, are also a feature of each module. Thus students encounter each other in module-specific contexts and therefore already have a sense of collective identity, criterion 3 , in which they feel comfortable.

The module advice forum therefore combines these individual module identities to provide a platform for students to belong to a wider academic community. The focus on the shared goal, criterion 1, of providing advice on module choice gives the forum a specific purpose for a bounded learning community, rather than the organic remit of a community of practice. The expectation is that students will give each other a lot of advice regarding module choice based on their own learning experiences, with the staff prompting, providing facts and relevant opinions. The prompting often includes referring students to particular resources on the subject site or encouraging individual student contact with one of the advisory staff. This collaboration, criterion 4, means that not only do students learn from each other, but also contribute to suggestions for further resources which are then picked up by the academic staff. Indeed the mutual appropriation, criterion 7 , of the forum, where students are both learners and teachers, is evident from the rich contribution by students at various stages of their learning journey. Many of the part-time tutors have previously been OU students, making them a particularly rich source of advice.

The importance of providing safe and supporting conditions, criterion 2, is established by staff acting as moderators in the forum who guide the discussions and ensure that all interactions are respectful. This is highlighted by a recent forum posting from a student:

"I would like to express my heartfelt thanks to everyone within this community ... I have had ups and downs and yes, you are on your own, but that is when the support gleaned from loved ones and fellow students becomes ever more important to you. Which is where these forums have come into their own ... OK, I sometimes (well, rarely if I'm honest) respond and this is my debut in thread commencement.

Despite that, they are the second thing I look when I sign in! ... the inclusivity of it all is a testament to behold."

As advice ranges so widely, for instance on future study plans, how different modules may help with future careers and what it is like to study a particular module, there are numerous opportunities for students to provide informal feedback to the School on both the content of what is delivered in the mathematics and statistics curriculum and all aspects of the mathematics and statistics student experience. This provides the perfect platform for Progressive discourse towards knowledge building, criterion 6 . As one student expressed, it is "the most interesting forum provided by the OU".

As the forum has developed and engagement increased, it has provided students with the opportunity to engage more fully in related matters such as curriculum development and 
delivery of student support. It thus also became a platform for the mathematics and statistics student voice to be heard. It should be emphasised that this engagement complements the long-standing formal representation of students on decision-making committees and formal feedback surveys.

The advice forum provides the perfect platform for such informal feedback. Comments from students have resulted in development of new curriculum, changes to degree structures, changes to assessment, production of new resources to aid with particular requirements such as exam technique, changes to software provision, changes to how additional requirements are provided for certain modules, and many more. Some of these changes are small tweaks to improve the overall student experience: some are major curriculum changes. It is important to concentrate on using feedback in order to build a culture of engagement and partnership (Howson, 2014). The forum has been held up as the blueprint to which all Schools in the OU should aspire to in terms of providing such a space for student feedback.

\section{Summary}

In a face-to-face environment there are a number of ways in which relationships between staff and students can be fostered in order to create a community of learners. These might include: introducing group work early; creating opportunities to talk to students outside of timetabled contact hours; and establishing peer tutoring and mentoring (Bamber \& Jones, 2014). Creating a community of learners in a distance-learning context similarly requires activities which are complementary to the study itself. However, social opportunities are harder to orchestrate. It is also important for staff to respond to individual needs when considering the student experience, it is often the quality, not the quantity which is important in such interactions. Such interaction can take a variety of forms which might include, for example, discussion of career plans (Coates, 2010).

There is a need to engage students in a variety of ways in order to elicit feedback and Universities are increasingly focussed on offering a student experience which fosters engaged learning communities. Price et al
(2011) state "To move beyond 'customer satisfaction' approaches to evaluating the student experience, a more holistic, socially embedded conceptualisation of feedback is needed'. In order to effectively use the student voice, students must be part of a learning community in order to actively represent opinions regarding their own learning experience.

Whilst many universities are grappling with new ways of developing and promoting such a learning environment, this holds particular challenges for distance-learning students. However, a society which is increasingly reliant on technology provides opportunities which can be harnessed in order to facilitate such a community. Although this is particularly important for distance-learners who are remote from campus, an online community provides opportunities to engage students who are facing challenges which may prevent face-toface engagement with their subject community in a traditional university, such as the need to take on paid work or timetabling constraints resulting from interdisciplinary study.

This paper has described how the Open University has created a platform for an active mathematics and statistics learning community consisting of students, part-time tutors, academics and student support staff, all aligned to the mathematics and statistics discipline. The focussed nature of the module advice forum supports each of the seven criteria which Wilson et al (2004) outline as necessary for a bounded learning community to be realised.

The forum enables students to act both as the learner and instructor as they progress through their studies, with staff engagement to guide the discussion and resolve any conflicts. Whilst the focus on module choice provides a clear purpose for all the community to engage, the scope is wide enough to enable informal feedback on wider student issues.

The associated resources support students throughout their student journey and often the advice in the forum is to highlight an appropriate resource which would be of particular value for the student at that stage in their journey.

All universities are examining their own student experience and looking for ways to enable 
students to feel part of a learning community. Online forums focussing on a bounded area, in the example given here, that of module advice, offer a way of augmenting face-to-face social and formal events to enable a sense of community and provide feedback opportunities. The success of this forum lies in active engagement from all staff (academic, part-time tutors and student support staff) and students providing a vibrant community of learners focussed on a common goal.

\section{References}

Bamber, V. \& Jones, A. (2014) Challenging students: Enabling inclusive learning. In Fry, $\mathrm{H}$., Ketteridge S. \& Marshall, S.A. A Handbook for Teaching and Learning in Higher Education: Enhancing academic practice, 152-168. Oxon: Routledge.

Coates, H. (2010) Development of the Australasian survey of student engagement (AUSSE). Higher Education, 660, 1-17. DOI: 10.1007/s10734-009-9281-2

Crosling, G., Thomas, L. \& Heany, M. (2008) Improving Student Retention in Higher Education - The role of teaching and learning. London:Routledge.

Foster, E., Lawther, S., Keenan, C., Bates, N., Colley, B. \& Lefever R. (2012) The HERE Project: Higher Education: Retention \& Engagement. London: Paul Hamlyn Foundation.

Hilliam, R. \& Williams, G. (2019a) Academic and pastoral teams working in partnership to support distance learning students according to a curriculum area. Higher Education Pedagogies Journal, 4(1), 32-40. DOI: 10.1080/23752696.2019.1606674

Hilliam, R. \& Arrowsmith, G. (2019b) Enhancing the student experience with the use of a dedicated subject website. MSOR Connections, 17(2), 39-45. DOI: 10.21100/msor.v17i2.947

Howson, C.B.K. (2014). Feedback to and from students: Building an ethos of student and staff engagement in teaching and learning. In Fry, H., Ketteridge, S. and Marshall, S.A. Handbook for Teaching and Learning in Higher Education:
Enhancing academic practice, 123-138. Oxon:Routledge

Kuh, G.D., Grace, T.M., Shoap, R., Kinzie, J. \& Gonyeq, R.M. (2008). Unmasking the effects of student engagement on first-year college grades and persistence. The Journal of Higher Education, 79(5), 540-563. DOI: 10.1080/00221546.2008.11772116

Lave, J. \& Wenger, E. (1991) Situated Learning: Legitimate peripheral participation. Cambridge, UK: Cambridge University Press.

Price, M., Handley, K. \& Millar, J. (2011). Feedback-focussing attention on engagement. Studies in Higher Education, 36(8), 879-896. DOI: 10.1080/03075079.2010.483513

Tinto, V. (2004) Student Retention and Graduation: Facing the Truth, Living with the Consequences. Occasional Paper 1. Washington DC: The Pell Institute.

Wells, P. (1999) Different and Equal: Fostering independent in a learning community. In Retallick, J., Cocklin, B. and Commbe, K. Learning Communities in Education: Issues, strategies and contexts. UK: London, Routledge.

Wenger, E. (1998). Communities of Practice: Learning, meaning and identity. Cambridge, UK: Cambridge University Press.

Wilson, B.G., Ludwig-Hardman, S., Thornam, C.L. \& Dunlap, J.C. (2004) Bounded Community: Designing and facilitating learning communities in formal courses. International Review of Research in Open and Distance Learning, 5(3). DOI: 10.19173/irrodl.v5i3.204

Zhao, C. \& Kuh, G.D. (2004). Adding Value: Learning Communities and Student Engagement. Research in Higher Education, 42(5), 115-138. DOI: 10.1023/B:RIHE.0000015692.88534.de 